\title{
Evaluation of sea-ice thickness reanalysis data from the coupled ocean-sea-ice data assimilation system TOPAZ4
}

\section{Article}

Cite this article: Xiu Y, Min C, Xie J, Mu L, Han $B$, Yang Q (2021). Evaluation of sea-ice thickness reanalysis data from the coupled ocean-sea-ice data assimilation system TOPAZ4. Journal of Glaciology 67(262), 353-365. https://doi.org/10.1017/jog.2020.110

Received: 13 May 2020

Revised: 1 December 2020

Accepted: 3 December 2020

First published online: 13 January 2021

Key words:

Sea ice; TOPAZ4; sea-ice modelling

Author for correspondence:

Qinghua Yang,

E-mail: yangqh25@mail.sysu.edu.cn (c) The Author(s), 2021. Published by Cambridge University Press. This is an Open Access article, distributed under the terms of the Creative Commons Attribution licence (http://creativecommons.org/licenses/by/4.0/), which permits unrestricted re-use, distribution, and reproduction in any medium, provided the original work is properly cited.
Yongwu Xiu ${ }^{1,2}$, Chao $\mathrm{Min}^{1,2}{ }^{(D}$, Jiping $\mathrm{Xie}^{3}$, Longjiang $\mathrm{Mu}^{4}$, Bo $\mathrm{Han}^{1}$ and Qinghua Yang ${ }^{1,2}$ (D)

\footnotetext{
${ }^{1}$ School of Atmospheric Sciences, Sun Yat-sen University, and Southern Marine Science and Engineering Guangdong Laboratory (Zhuhai), Zhuhai 519082, China; ${ }^{2}$ State Key Laboratory of Numerical Modeling for Atmospheric Sciences and Geophysical Fluid Dynamics, Institute of Atmospheric Physics, Chinese Academy of Sciences, Beijing, China; ${ }^{3}$ Nansen Environmental and Remote Sensing Center, Bergen N5006, Norway and ${ }^{4}$ Alfred Wegener Institute Helmholtz Centre for Polar and Marine Research, Bremerhaven 27570, Germany
}

\section{Abstract}

With the assimilation of satellite-based sea-ice thickness (SIT) data, the new SIT reanalysis from the Towards an Operational Prediction system for the North Atlantic European coastal Zones (TOPAZ4) was released from 2014 to 2018. Apart from assimilating sea-ice concentration and oceanic variables, TOPAZ4 further assimilates CS2SMOS SIT. In this study, the 5-year reanalysis is compared with CS2SMOS, the Pan-Arctic Ice-Ocean Modeling and Assimilating System (PIOMAS) and the Combined Model and Satellite Thickness (CMST). Moreover, we evaluate TOPAZ4 SIT with field observations from upward-looking sonar (ULS), ice mass-balance buoys, Operation IceBridge Quicklook and Sea State Ship-borne Observations. The results indicate TOPAZ4 well reproduces the spatial characteristics of the Arctic SIT distributions, with large differences with CS2SMOS/PIOMAS/CMST mainly restricted to the Atlantic Sector and to the month of September. TOPAZ4 shows thinner ice in March and April, especially to the north of the Canadian Arctic Archipelago with a mean bias of $-0.30 \mathrm{~m}$ when compared to IceBridge. Besides, TOPAZ4 simulates thicker ice in the Beaufort Sea when compared to ULS, with a mean bias of $0.11 \mathrm{~m}$ all year round. The benefit from assimilating SIT data in TOPAZ4 is reflected in a 34\% improvement in root mean square deviation.

\section{Introduction}

Arctic sea ice is an important component of the global climate system (Serreze and Meier, 2019) and plays a crucial role in the global ocean circulation (Sévellec and others, 2017). In the context of climate change, Arctic sea ice has undergone a rapid decline during the past decades and hence, gains great attention from climate research and social industrial applications (Comiso and Hall, 2014; Meier and others, 2014; Stroeve and Notz, 2015). For example, the rapid decline of Arctic sea ice in recent years has spurred more commercial traffic through the Arctic routes with significantly reduced distance from Asia to Europe (Melia and others, 2017; Zhang and others, 2020). In the Central Arctic, the ocean is covered by close pack ice and compact pack ice, and the navigability is primarily controlled by the sea-ice thickness (SIT) and sea-ice concentration (SIC) along the route. Among all the sea-ice properties, SIT is important, because changes in its distribution can affect the ocean-atmosphere heat fluxes especially during the fall period (Kurtz and others, 2011). However, until the 1990s, our knowledge of SIT distribution was hampered by the sparsity of observations except for some submarine records (Rothrock and others, 1999). Uotila and others (2019) demonstrated the large differences of sea-ice volume (SIV) and SIT in ten ocean and sea-ice reanalysis products in their Polar Ocean Reanalyses (ORA) Intercomparison Project. With respect to the Ice Thickness Regression Procedure (Lindsay and Schweiger, 2015) data in February-March, most of these products underestimate SIT to the north of the Canadian Arctic Archipelago (NOCAA) and the north of Greenland and the Fram Strait, but overestimate SIT over the Eurasian shelves. This exposes the lack of direct constraints on SIT, which is a common deficiency of all reanalysis products.

Estimating of the Arctic sea-ice extent (SIE) and SIT relies upon numerous geophysical parameters which could result in large uncertainties. In contrast to the successes of deriving SIC and SIE from satellite (Cavalieri and Parkinson, 2012), SIT retrieval still has large uncertainties (Kwok and Cunningham, 2015). With an assumption of hydrostatic equilibrium, SITs can be estimated from the freeboard measurements boarded on satellite altimeters, for example Envisat since 2002 (Connor and others, 2009; Hendricks and others, 2018), ICESat since 2003 (Kwok and others, 2009) and CryoSat-2 since 2010 (Ricker and others, 2014). The estimated SITs still have large uncertainties, which come along with the utilization of the snow depth (Warren and others, 1999) and the assumption of hydrostatic equilibrium. Since 2010, the thickness for thin ice $(<1.0 \mathrm{~m})$ can be retrieved by the brightness temperature observations measured by Soil Moisture and Ocean Salinity (SMOS) satellite (Kaleschke and others, 
2010; Tian-Kunze and others, 2014), although the SMOS thickness data may suffer from inaccurate boundary conditions introduced by the sea ice-ocean model (Tian-Kunze and others, 2014). Exploiting the complementary characters of CryoSat-2 and SMOS SITs, Ricker and others (2017) further merged them together into an Arctic-wide SIT dataset, CS2SMOS. Retrieving SIT from satellite assumes that the peak reflection in the radar altimetry data originates from snow/ice interface (Laxon and others, 2003). However, it is difficult to separate the echoes from the open water and melt ponds during the melting season, all satellitederived SITs are only available in the cold seasons, from October to March.

In recent years, the satellite observed SIC and SIT have been assimilated into ice-ocean coupled models and the results showed promising improvements in reconstructing the time series of Arctic SIT (Yang and others, 2014, 2016; Posey and others, 2015; Xie and others, 2016, 2018; Mu and others, 2018a). In particular, a widely used sea-ice reanalysis, TOPAZ4, is accessible through the Copernicus Marine Environment Monitoring Service (CMEMS; https://resources.marine.copernicus.eu) portal with the product id of ARCTIC_REANALYSIS_PHYS_002_003. This reanalysis product is extended yearly, based on a coupled ocean and sea-ice assimilation system. In this system, the hybrid coordinate ocean model (HYCOM; Chassignet and others, 2006) is used with 28 hybrid layers in vertical, coupled with a sea-ice model. The sea-ice model is composed of simple thermodynamics with only one sea-ice category and ice dynamics (Bouillon and others, 2013) modified from the elastic-viscousplastic rheology (Hunke and Dukowicz, 1997). With a varied horizontal resolution of $12-16 \mathrm{~km}$, the model can cover the whole Arctic basin but cuts at the Bering Strait where a seasonal inflow is imposed with a transport based on the observational estimate. The Deterministic Ensemble Kalman Filter (Sakov and others, 2012) is implemented with 100 ensemble members in the system which is capable to assimilate many different kinds of ocean and ice observations weekly, including along-track sealevel anomaly, sea surface temperature (SST), in situ profiles of temperature and salinity, SIC and sea-ice drift products from Ocean and Sea Ice Satellite Application Facility (OSISAF). The TOPAZ4 reanalysis is forced by ERA-interim in the whole time period, and the finally released product is interpolated into horizontal grids with a resolution of $12.5 \mathrm{~km}$ and published twice a year through the CMEMS portal. Also, being an operational Arctic sea ice-ocean forecast system, TOPAZ4 provides 10 days forecasts for ocean physics and biogeochemistry in the Arctic by the CMEMS portal online. The SIT in TOPAZ4 represents gridcell-averaged ice thickness, also called effective ice thickness (Schweiger and others, 2011), which is the averaged SIT within one model grid. Xie and others (2017) quantitatively evaluated the SIT in TOPAZ4 against in situ measurements and satellitebased observations during 1991-2013. The results revealed large biases $(\sim 1.1 \mathrm{~m})$ of SIT compared to ICESat and IceBridge. To fill the SIT gap between reanalysis and observations, Xie and others (2018) have tested the impact of assimilating CS2SMOS SIT into TOPAZ4 and the results showed the potential to further improve the SIT representation in TOPAZ4 reanalysis. However, the test was limited by the short experiment time only 1 year from March 2014 to March 2015 and the used observations for validation only a few categories of SIT observations. A comprehensive evaluation of the reanalysis system remains to be carried out.

Recently, the TOPAZ4 reanalysis has been extended more than 5 years, since in 2014 when the SIT from CS2SMOS started to be assimilated and provides a good opportunity for us to evaluate the SIT simulation skill. To help improve the system further, available in situ Arctic SIT observations have been collected as references.
They include SITs from the upward-looking sonar (ULS), ice mass-balance (IMB) buoys, Operation IceBridge Quicklook (OIQ) and Sea State Ship-borne observations (SSO). SIT data from other models are also used for intercomparison, for example the Pan-Arctic Ice-Ocean Modeling and Assimilation System (PIOMAS) reanalysis data (Zhang and Rothrock, 2003), which is usually regarded as a referenced modelling dataset in the Arctic, especially for year-round time series of SIT/SIV. In addition, the newly developed Combined Model and Satellite Thickness (CMST; Mu and others, 2018a) dataset is added for the intercomparison. CMST uses Local Error Subspace Transform Kalman Filter ( $\mathrm{Mu}$ and others, 2018a, 2018b) to jointly assimilate SIT from SMOS and CryoSat-2 individually from 2010 to 2016. CMST SIT has been systematically evaluated by $\mathrm{Mu}$ and others (2018a) to compare with in situ observations and the PIOMAS SIT in the Arctic, the results showed promising reliability for CMST SIT.

This paper is organized as follows: In section 2, we provide the information of the SIT datasets used for evaluation, including in situ observations, satellite remote-sensing data and numerical model data. In section 3, we describe the methods used for evaluation. In section 4 , we present the results. The discussion and conclusion are given in section 5 .

\section{Data for evaluation}

\subsection{PIOMAS SIT dataset}

The Pan-Arctic Ice-Ocean and Assimilating System (PIOMAS) is a coupled sea ice-ocean model with SIC and SST assimilation using optimal interpolation (Lindsay and Zhang, 2006; Schweiger and others, 2011). It applies a 12-category SIT and enthalpy distribution (TED model; Zhang and Rothrock, 2003). The system is forced by NCEP/NCAR reanalysis data. PIOMAS overestimated SIT for thin ice in the Beaufort Sea area and underestimated the thick ice around the north coast of Greenland and Canadian Arctic Archipelago (CAA) when compared to IceBridge (Wang and others, 2016). In this study, the PIOMAS v2.1 is used as one reference data for SIT evaluation (http://psc.apl.uw.edu/ research/projects/arctic-sea-ice-volume-anomaly).

\subsection{CMST SIT dataset}

CMST is generated by a regional, pan-Arctic ice-ocean model (Losch and others, 2010) based on the Massachusetts Institute of Technology general circulation model (MITgcm; Marshall and others, 1997). For sea ice, it uses the viscous plastics rheology (Hibler, 1979; Zhang and Hibler, 1997) in ice dynamics, and the one-layer, zero-heat capacity formulation in thermodynamics (Semtner and Albert, 1976). Forcing by the atmosphere fields from the United Kingdom Met Office (UKMO) Ensemble Prediction System, CMST product is generated from 2011 to 2016 with a resolution of $\sim 18 \mathrm{~km}$. The system uses the LESTKF coded in the Parallelized Data Assimilation Framework (PDAF; Nerger and Hiller, 2013) to assimilate SIT from SMOS $(<1 \mathrm{~m})$ and CryoSat-2 (Mu and others, 2018a, 2018b) individually, and SIC from the Integrated Climate Data Center.

\subsection{CS2SMOS SIT dataset}

The complementary characteristics of the SIT products in CroySat-2 (Ricker and others, 2014; Tilling and others, 2016) and SMOS (Tian-Kunze and others, 2014) enable the combination of the data with an optimal interpolation scheme. The merged weekly product, referred to as CS2SMOS (Ricker and others, 2017; https://data.seaiceportal.de/), covers the whole 
Arctic. CS2SMOS shows some skills with a reduction of $0.7 \mathrm{~m}$ in terms of RMSD over the CryoSat-2 product when compared to the airborne thickness data. However, in mixed first-year and multiyear ice regimes such as in the Beaufort Sea, CS2SMOS has larger biases than CryoSat-2 does (Ricker and others, 2017). In this study, the CS2SMOS v1.3 ice thickness product is used as a referenced satellite-derived dataset for SIT evaluation.

\subsection{ULS SIT dataset}

To investigate basin-scale mechanisms regulating fresh water content in the Arctic Ocean and particularly in the Beaufort Gyre, Beaufort Gyre Exploration Project (BGEP, https://www.whoi. edu/website/beaufortgyre/home) program has been launched since 2003. The ULSs have been regularly deployed to measure sea-ice draft (Melling and others, 1995). In this study, SIT is estimated by multiplying the sea-ice draft with a factor of 1.1 (Nguyen and others, 2011) without further considering the varied ice types and snow thickness. The estimated error of the sea-ice draft measurements is $\pm 5-10 \mathrm{~cm}$ based on the analysis from Krishfield and Proshutinsky (2006), but not available in the original dataset. Compared with other in situ observations, BGEP can provide year-round SIT. We use these observational SIT data from 2014 to 2018 for the evaluation.

\subsection{IMB buoy SIT dataset}

The IMB buoys are designed to measure and attribute thermodynamic changes in the mass balance of the sea-ice covered area (http://imb-crrel-dartmouth.org; Perovich and others, 2009). The equipment to measure SIT consists of two acoustic sounders which are mounted above and below the ice, respectively. The uncertainty of measured SIT is within $5 \mathrm{~mm}$ (Richter-Menge and others, 2006), which is not considered in this study. Although comparing the Eulerian model results with the Lagrangian IMB buoy SIT may lead to a dilemma somehow, we expect a maximum utilization of useful information for the evaluation such as the SIT evolution in IMB and TOPAZ4. We select 15 buoys for validation from 2014 to 2015, as there is no archived data from 2016 to 2018 .

\subsection{OIQ SIT dataset}

To bridge the gap between NASA's Ice, Cloud and Land Elevation Satellite (ICESat) and ICESat-2, NASA launched Operation IceBridge flight campaigns to measure snow depth and SIT from March to May (https://nsidc.org/data/IceBridge/). The campaigns have a close-up view of the maximum ice thickness of its annual cycle with a good spatial coverage over the western Arctic basin. The observation has a spatial resolution of $40 \mathrm{~m}$ (Kurtz and others, 2013) and observations falling into one model grid are averaged and then used for the evaluation. The uncertainty comes along with the usage of climatology snow density and in situ sea-ice density during the calculation of the IceBridge SIT. The airborne SITs have been reported to be slightly low-biased by $\sim 5 \mathrm{~cm}$ compared to the in situ observation (King and others, 2015). We use the OIQ products from 2014 to 2018, there are 51 flight campaigns.

\subsection{SSO SIT dataset}

The Sea State field campaign was conducted in the Beaufort Sea and Chukchi Sea in the autumn of 2015, which was dedicated to collect and process data from ship-borne atmosphere, ice and ocean measurements and to characterize the near-surface environment (https://digital.lib.washington.edu/researchworks/handle/
1773/41864; Persson and others, 2018). During this campaign over the autumn freeze-up period, large numbers of atmosphere-ice-ocean environmental parameters have been measured in the area of new growing ice and ice edge. For SIT it was measured by a combination of manual observation techniques and sensor observation techniques. In this study, a 10-minutes averaged SIT product is used, which was calculated from surface temperatures measured by the KT-15 IR thermometers.

All the locations of in situ observations are applied to the different sea areas according to NSIDC Multisensor Analyzed Sea Ice Extent (MASIE), for example, the Chukchi Sea, the Beaufort Sea, the Central Arctic and NOCAA. They are plotted in Figure 1 in this study.

\section{Methods for evaluation}

The TOPAZ4 SIT (referred to as TP4 in the equations for simplicity) is evaluated based on the datasets listed in Section 2 (collectively referred to as Ref in the equations). Compared with in situ observations (except for IMB observations), we select the RMSD, the bias and the correlation coefficient (CC) as evaluation metrics. When comparing with other gridded products, such as PIOMAS, CMST and CS2SMOS, relative difference (RD) is used to quantify the comparison as done in Min and others (2019). These metrics can be calculated as follows:

$$
\begin{gathered}
\mathrm{RMSD}=\sqrt{E\left[(\mathrm{TP} 4-\mathrm{Ref})^{2}\right]}, \\
\text { bias }=E(\mathrm{TP} 4-\mathrm{Ref}), \\
\mathrm{CC}=\frac{E[(\mathrm{TP} 4-E(\mathrm{TP} 4))(\operatorname{Ref}-E(\operatorname{Ref}))]}{\sigma_{\mathrm{TP} 4} \sigma_{\mathrm{Ref}}}, \\
\mathrm{RD}=\frac{\mathrm{TP} 4-\operatorname{Ref}}{\operatorname{Ref}} \times 100 \%,
\end{gathered}
$$

where the operator of $E$ represents the expectation, expressed by the spatial or temporal average. Note that $\sigma_{\mathrm{TP} 4}$ and $\sigma_{\mathrm{Ref}}$ are the standard deviation of SIT in TOPAZ4 and referred datasets.

SIT in IMB and TOPAZ4 have different representations. TOPAZ4 SIT represents effective SIT, which is the average within the model grid, while IMB buoy measures one particular ice floe. Within one model grid (larger than $10 \mathrm{~km}$ ), the real SIT could change dramatically, thus the SIT from IMB hardly represents the SIT in one model grid. To utilize the IMB data as far as possible, it would be more valuable to compare the SIT temporal variability rather than the exact value. The centred RMSD (CRMSD) that removes the mean of the time series generally meets the demand. Following $\mathrm{Mu}$ and others (2018a):

$$
\text { CRMSD }=\sqrt{E\left[\left(\left(\mathrm{TP} 4-E(\mathrm{TP} 4)-(\mathrm{Ref}-E(\mathrm{Ref}))^{2}\right]\right.\right.},
$$

In order to increase visualization, we also plot all statistical metrics in one Taylor Diagram, which requires the following formula to be satisfied (Taylor, 2001):

$$
\left(\frac{\mathrm{CRMSD}}{\sigma_{\mathrm{ref}}}\right)^{2}=\left(\frac{\sigma}{\sigma_{\text {ref }}}\right)^{2}+1-2 \mathrm{C} \frac{\sigma}{\sigma_{\text {ref }}},
$$

where $\sigma$ and $\sigma_{\text {ref }}$ are the standard deviation from the model and the references, respectively. To achieve this, we normalize the 


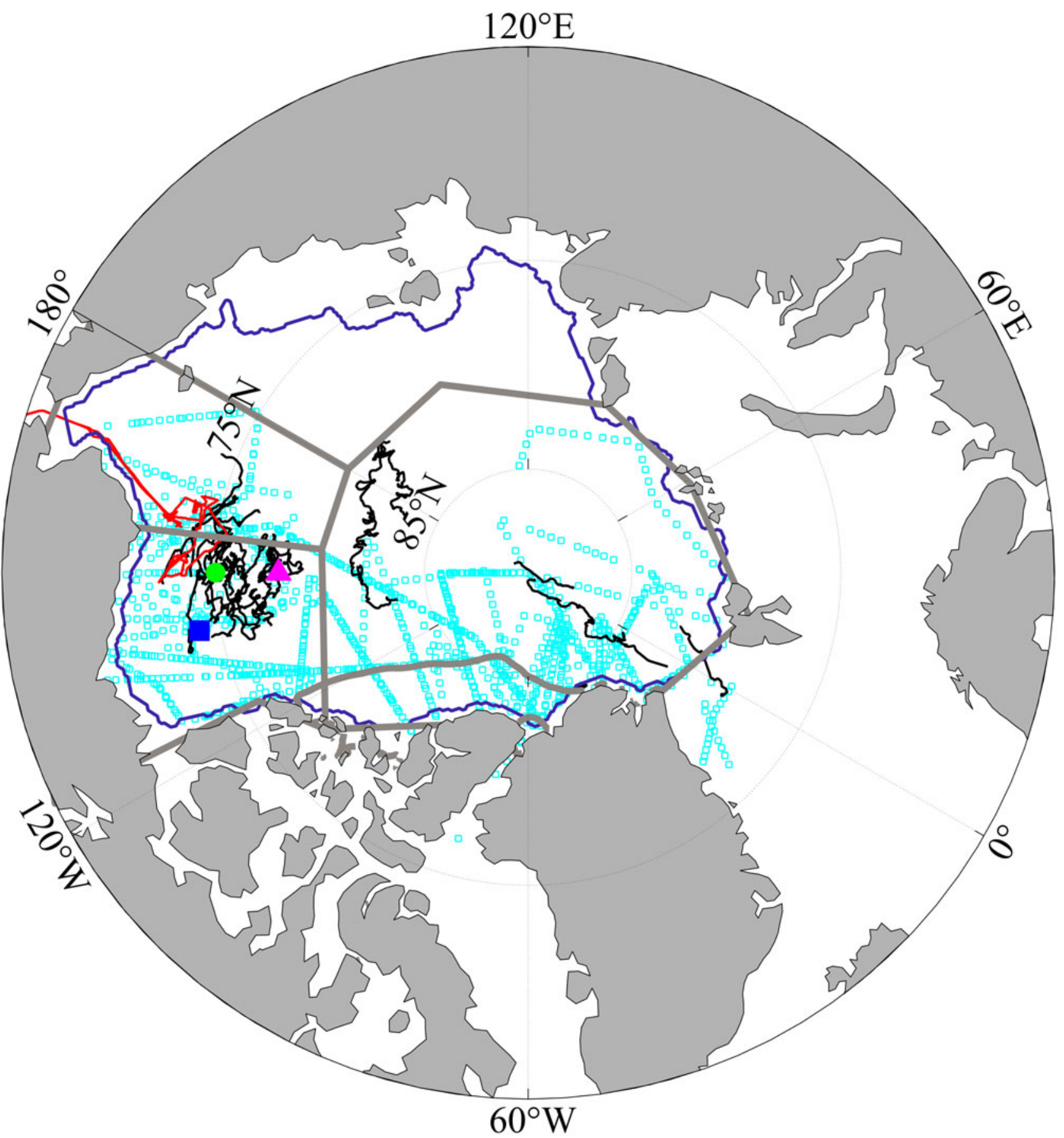

Fig. 1. Locations for all the observations used in this study. The blue square, green circle and magenta triangle represent the ULS locations of $B G E P \_A$, BGEP_B, BGEP_D, respectively. The black lines represent the IMB buoy routes. The cyan squares are the locations of Operation IceBridge Quicklook. The red line shows the track of Sea State Observation. The SIV is calculated over the area enclosed by the purple curve. The gray lines represent the boundary of different sea areas based on NSIDC MASIE, (a) the Chukchi sea, (b) the Central Arctic, (c) the Beaufort Sea and (d) north of the CAA.

standard deviations and the CRMSDs by dividing the standard deviations of the referred observations.

Considering that different maps and resolutions are applied to the gridded products, we only calculate the SIV on the overlapped coverages within the purple curve (Fig. 1). The gridded products, including CS2SMOS, PIOMAS and CMST are linearly interpolated into the mesh grid of TOPAZ4. After that, the SIV is calculated based on the effective SIT (SIT ${ }_{\text {eff }}$ ) and the area of the grid $\left(S_{\text {grid }}\right)$ as follows:

$$
\mathrm{SIV}=\operatorname{SIT}_{\text {eff }} \times S_{\text {grid }}
$$

\section{Results}

\subsection{Spatial distribution of SIT in March and September}

Arctic SIV in PIOMAS usually reaches its maximum in April. Since CS2SMOS does not cover the entire April, we choose averaged March SIT instead for intercomparison and evaluation. Averaged SIT in September has also been calculated to gain an insight into the performance of TOPAZ4 during the minimum SIT period. Comparisons of the SIT spatial distribution are performed against PIOMAS, CMST and CS2SMOS in these 2 months. Note that CS2SMOS data are only available in the freezing season. In this study, the overlapped period between 
a

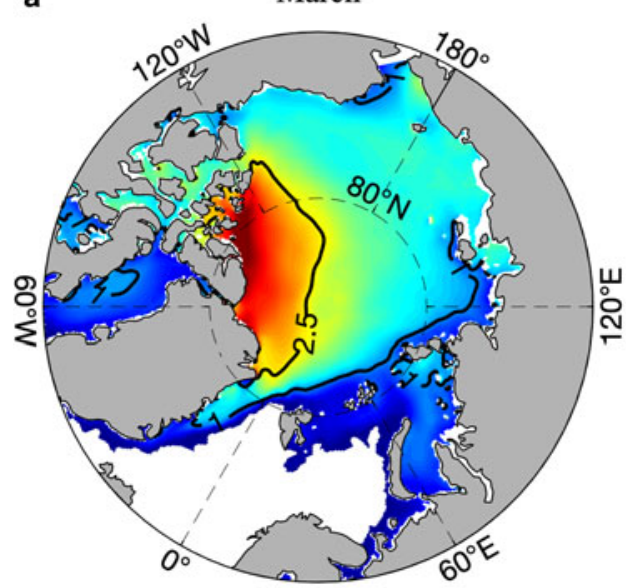

b

beptember

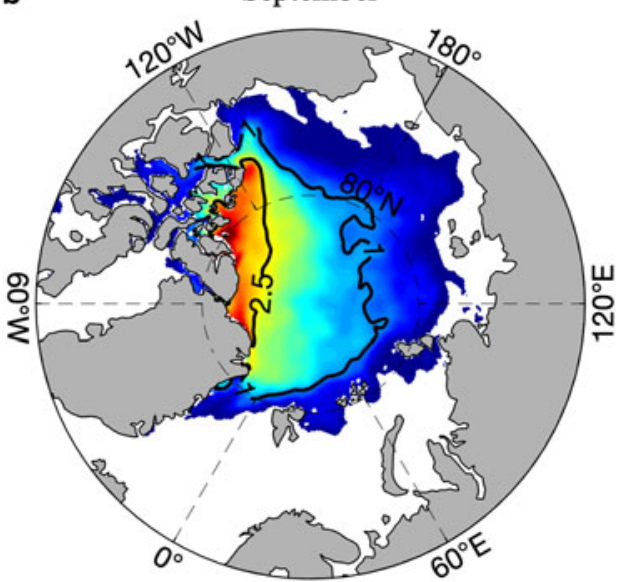

Fig. 2. Five-year (2014-18) averaged SIT in TOPAZ4 for March (a) and September (b). The contours represent 2.5 and $1 \mathrm{~m}$.

TOPAZ4 and CMST is only from 2014 to 2016, while the period used for the other datasets is from 2014 to 2018.

As shown in Figure 2, in March, the TOPAZ4 SIT is found thinner than $1.0 \mathrm{~m}$ over the Barents Sea, the Kara Sea, the Laptev Sea and the Baffin Bay. The central Arctic is covered by thick ice of $\sim 2.5 \mathrm{~m}$ and the multiyear ice thicker than $4.0 \mathrm{~m}$ appears along the northern coast of the CAA. Following the melting season, the sea-ice area in September has reduced $~ 58 \%$ from its area in March. The ice-free area is found along the coast of the Asian Continent.

The differences and RD between TOPAZ4 and other gridded products are shown in Figures 3, 4, respectively.

In March, due to the influence of assimilating CS2SMOS SIT, TOPAZ4 fits to CS2SMOS very well, with a minimum difference of only $0.04 \mathrm{~m}$ and a minimum RMSD of $0.20 \mathrm{~m}$. The major difference is along the eastern coast of the Greenland. By fusing SIT from CryoSat-2 and SMOS, although in different ways, TOPAZ4 and CMST show some agreements. The differences between TOPAZ4 and CMST mainly locate in the American Sector, for example, the NOCAA, the north of Greenland. When compared with PIOMAS, TOPAZ4 also shows reasonable SIT to the NOCAA, though SIT was underestimated in PIOMAS there (Schweiger and others, 2011; Wang and others, 2016). In September, sea ice in TOPAZ4 is much thicker than in PIOMAS and the difference reaches $1.5 \mathrm{~m}$ along the coast of the Parry Islands. The difference between TOPAZ4 and CMST shows a pattern of dipole with thicker ice in the Canada Basin and thinner ice along the northern coast of the Greenland. Statistically, in March, TOPAZ4 reproduces thinner ice than the other three products, with a mean difference of $-0.04 \mathrm{~m}$ for CS2SMOS, $-0.07 \mathrm{~m}$ for CMST and $-0.25 \mathrm{~m}$ for PIOMAS. In September, TOPAZ4 SIT is closer to CMST, with a difference of $-0.06 \mathrm{~m}$, but it is $0.21 \mathrm{~m}$ thicker than PIOMAS.

The RD shows some spatial and temporal variations. In March, the large RD mainly locates in the Atlantic Sector, especially in the Fram Strait and the Barents Sea (Figs 4b, c), where TOPAZ4 has thicker ice against PIOMAS and CMST. In September, the difference is mainly in the marginal sea-ice zone, such as the Beaufort Sea and the Eurasian Sector, with TOPAZ4 SIT 40\% thicker than PIOMAS and CMST (Figs 4d, e).

The SIV is also added for intercomparison, given in Figure 5. Considering that different geographical maps are applied to these datasets, for example, TOPAZ4 assumes the Bering Sea is ice-free whereas the CS2SMOS observations suggest the opposite, therefore only the volume within the area enclosed by the purple curve in Figure 1 is calculated using Eqn (7). Similarities and differences of SIV evolution are observed among these four products. Due to the assimilation of SIT from CryoSat-2 and SMOS, despite in different ways, the SIVs in TOPAZ4 and CMST show coherence, especially during the ice growth season. However, differences in the SIV evolutions are clearly presented. For example, SIV in TOPAZ4 fluctuates less than that in PIOMAS as TOPAZ4 reproduces thinner ice in March and thicker ice in September (Figs 3b, d). Besides, TOPAZ4 has a slower ice growth rate during the ice growth season than PIOMAS due to the slower ice growth rate in CS2SOMS. What is more, the melting onset date in TOPAZ4 is slightly later than that in PIOMAS and CMST.

\subsection{Evaluation of SIT against in situ measurements}

\subsubsection{Comparing with ULS SIT data}

The locations of ULS moorings are given in Figure 1, with BGEP_A, BGEP_B and BGEP_D moorings represented by dot, square and triangle, respectively. ULS measures SIT daily from 2014 to 2018. The SIT variations of ULSs and TOPAZ4 (with and without SIT assimilation) are illustrated in Figure 6.

After the SIT assimilation from CS2SMOS, not surprisingly, the mean correlation between TOPAZ4 and ULS SIT is relatively high (0.71). The normalized standard deviation of TOPAZ4 SIT is $0.83 \mathrm{~m}$. TOPAZ4 reproduces the SIT in the freezing season and also shows reasonable results in the melting hiatus. The bias (TOPAZ4 minus ULS) is $0.11 \mathrm{~m}$ averaged over the concerned year, with a lower value $(-0.06 \mathrm{~m})$ during March and April. Large bias exists in summer (June-July-August) with a mean value of $0.33 \mathrm{~m}$ and a mean RMSD of $0.62 \mathrm{~m}$ as given in Table 1 .

Some common deficiencies in TOPAZ4 are presented when compared with these three ULS observations. The melting onset date in TOPAZ4 is significantly later than that in ULS, especially for 2016-18. This shows some coincidences with SIV evolution in Figure 5. The large amplitude and high frequency of SIT variations are generally smoothed in the TOPAZ4 results. This is not surprising, because ULS captures SIT in one particular location, but TOPAZ4 SIT represents the gridcell-averaged value. Large misfits between ULS and TOPAZ4 exist in April 2015. The assimilated CS2SMOS SIT is responsible for the unexpected large reduction of SIT in TOPAZ4 on BGEP_D/B in 2015 
a TOPAZ4-CS2SMOS (Mar)

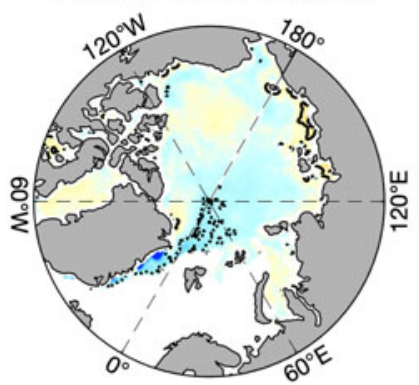

b TOPAZ4-PIOMAS (Mar)

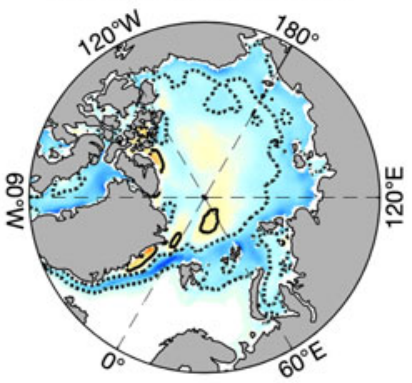

d TOPAZ4-PIOMAS (Sep)

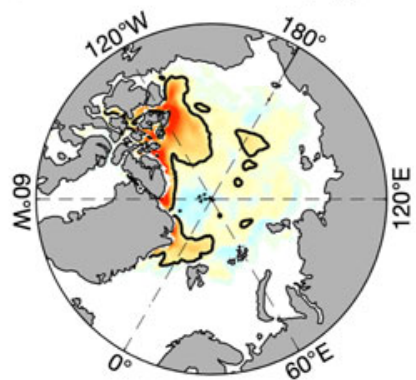

c TOPAZ4-CMST (Mar)

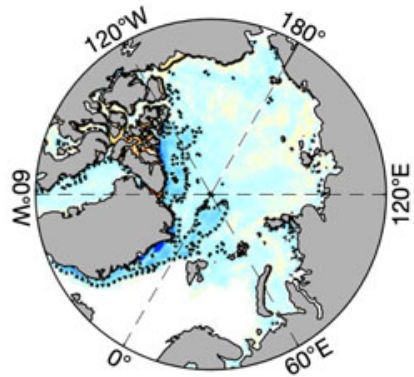

e TOPAZ4-CMST (Sep)

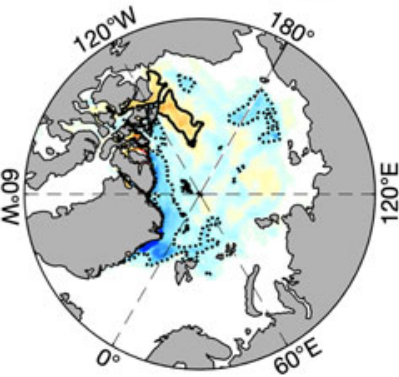

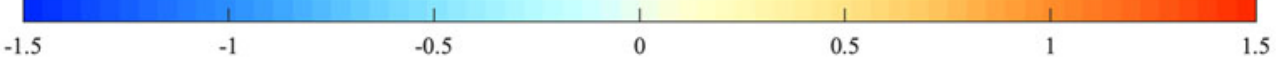

Fig. 3. Difference of SIT (in m) between TOPAZ4 and CS2SMOS (a), PIOMAS (b, d), CMST (c, e) in March (top panel) and September (bottom panel). Note that CS2SMOS is not available in September. The period used for CMST is 2014-16, while the period for the other datasets is 2014-18. For every panel, the solid (dashed) lines indicate the $0.3 \mathrm{~m}(-0.3 \mathrm{~m})$ isolines.

a TOPAZ4-CS2SMOS (Mar)

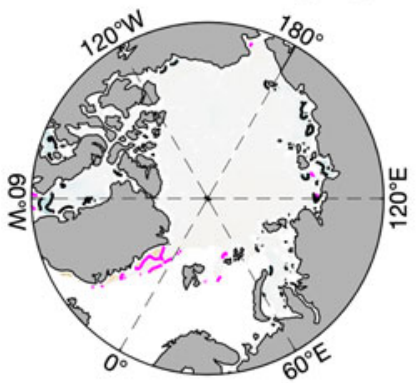

b TOPAZ4-PIOMAS (Mar)

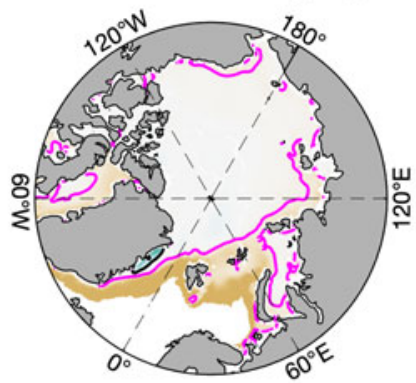

d TOPAZ4-PIOMAS (Sep)

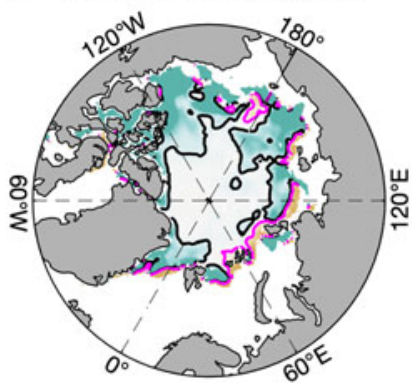

c TOPAZ4-CMST (Mar)

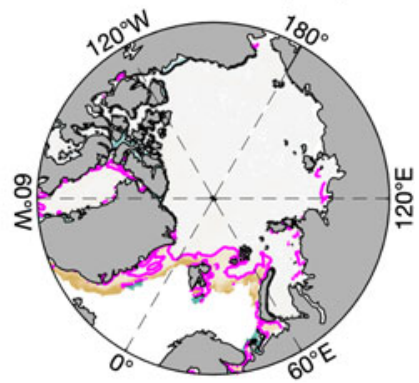

e TOPAZ4-CMST (Sep)

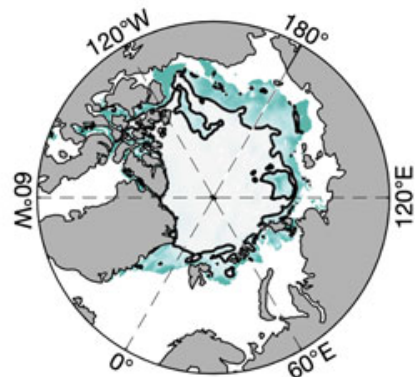

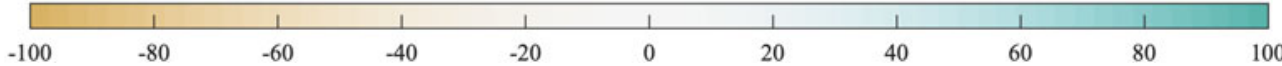

Fig. 4. Same as Figure 3, but for the spatial distribution of relative deviation (RD). For every panel, the dark (magenta) lines indicate $30 \%(-30 \%)$ isolines.

(compared to TOPAZ4 without SIT assimilation, Fig. 6, green line). The RMSDs for TOPAZ4 SIT at BGEP_A, BGEP_B and BGEP_D are $0.40,0.50$ and $0.58 \mathrm{~m}$, respectively.

Nevertheless, the benefits of assimilating CS2SMOS SIT are still clear, when comparing to the reanalysis without SIT assimilation, especially in the summer of 2015 and 2017. Assimilating CS2SMOS SIT contributes to a better initial condition at the beginning of melting season and a reasonable SIT change rate. Statistically, when compared to TOPAZ4 without SIT assimilation, the SIT assimilation contributes to an 


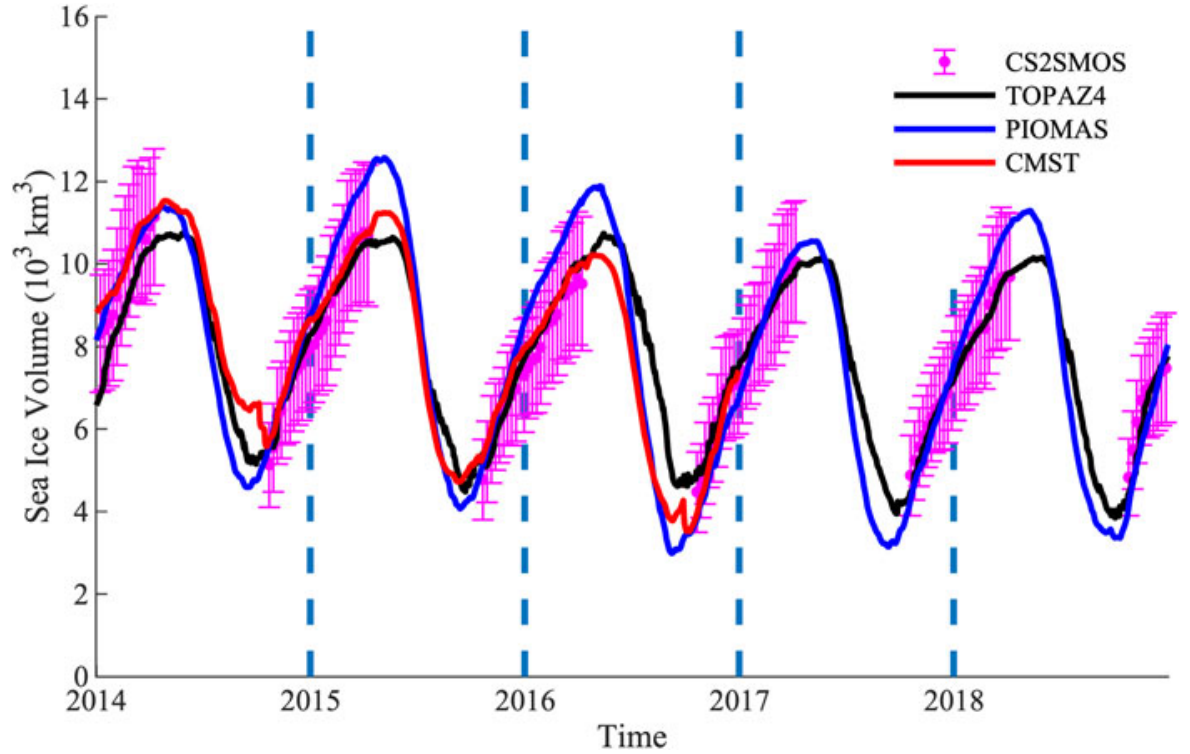

Fig. 5. Time series of sea ice volume (in thousands of $\mathrm{km}^{3}$ ) in TOPAZ4 (black line), PIOMAS (blue line) and CMST (red line). The magenta dot represents CS2SMOS SIV and the error bar is the corresponding uncertainty. The time coverage of these datasets is 2014-18 expect CMST (2014-16).

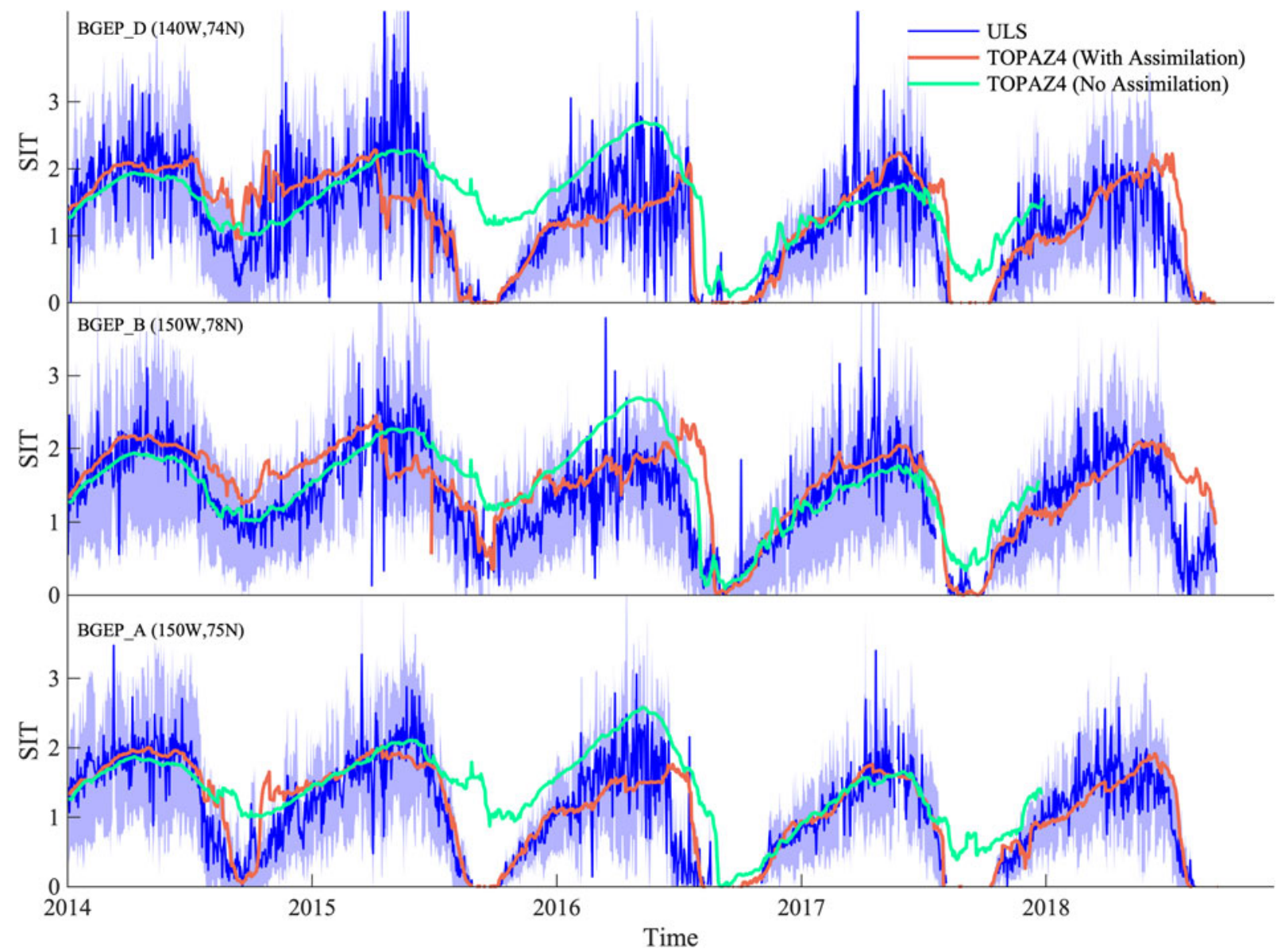

Fig. 6. Time series of SIT for BGEP ULS data (blue), TOPAZ4 data (with SIT assimilation, orange; without SIT assimilation, green) at BGEP moorings BGEP_A, BGEP_B, BGEP_D. The shadow areas represent standard deviation for ULS observations.

improvement of $\sim 60 \%$ in terms of bias, $15 \%$ in terms of RMSD and $8 \%$ in terms of CC. Our results agree with those from Xie and others (2018).

\subsubsection{Comparing with OIQ SIT data}

The Operation IceBridge Quicklook campaigns are conducted in March and April annually, which enable the evaluation of the
TOPAZ4 SIT during the freezing season. Observation during each campaign lasts only a few hours but covers a long distance over the western Arctic. The comparisons between IceBridge Quicklook and TOPAZ4 SIT are conducted annually. Further, we evaluate the performance of TOPAZ4 SIT over the Beaufort Sea, the Central Arctic and the Chukchi Sea based on the NSIDC MASIE concept (https://nsidc.org/data/masie/browse_regions). 
Table 1. Biases (in $\mathrm{m}$ ) and RMSDs (in $\mathrm{m}$ ) for the TOPAZ4 SIT based on ULS measured SIT in the Beaufort Sea in different seasons. 'All time' means the temporal-coverage of ULS from 2014 to 2018

\begin{tabular}{llccccc}
\hline Location & $\begin{array}{c}\text { Winter } \\
\text { (DJF) }\end{array}$ & $\begin{array}{c}\text { Spring } \\
(\mathrm{MAM})\end{array}$ & $\begin{array}{c}\text { Summer } \\
(\mathrm{JJA})\end{array}$ & $\begin{array}{c}\text { Autumn } \\
(\mathrm{SON})\end{array}$ & $\begin{array}{c}\text { All } \\
\text { time }\end{array}$ \\
\hline Bias & BGEP_A & 0.01 & -0.09 & 0.24 & 0.11 & 0.05 \\
& BGEP_B & 0.12 & 0 & 0.42 & 0.22 & 0.19 \\
& BGEP_D & -0.02 & -0.14 & 0.31 & 0.19 & 0.07 \\
& All & 0.04 & -0.12 & 0.33 & 0.17 & 0.11 \\
& locations & & & & & \\
RMSD & BGEP_A & 0.24 & 0.41 & 0.51 & 0.38 & 0.40 \\
& BGEP_B & 0.36 & 0.46 & 0.70 & 0.39 & 0.50 \\
& BGEP_D & 0.36 & 0.70 & 0.64 & 0.54 & 0.58 \\
& All & 0.32 & 0.52 & 0.62 & 0.43 & 0.50 \\
& locations & & & & & \\
\hline
\end{tabular}

TOPAZ4 SIT is also evaluated for the ridged area, NOCAA (Fig. 1).

Intuitively, TOPAZ4 simulates thinner ice in March and April, especially along the northern coast of the CAA, in the Beaufort Sea and the Fram Strait (Fig. 7a), where differences over $2 \mathrm{~m}$ are observed. The statistical metrics also support this conclusion, for example, TOPAZ4 SIT has a negative bias of $-0.21 \mathrm{~m}$, a CC of 0.66 and a RMSD of $0.92 \mathrm{~m}$ when compared with the IceBridge Quicklook. Nevertheless, the benefit of assimilating CS2SMOS SIT is obvious. The bias (RMSD) has been reduced to $-0.21 \mathrm{~m}$ $(0.92 \mathrm{~m})$ with a reduction of $81 \%(34 \%)$ when comparing to the results obtained by Xie and others (2017). This quantitatively demonstrates the promising impact of assimilating CS2SMOS into the system. The probability distribution function of the SIT difference between TOPAZ4 and IceBridge Quicklook is shown in Figure 7b. TOPAZ4 performs the best in 2014, with a maximum correlation of 0.71 (Fig. 8) and a bias of $-0.13 \mathrm{~m}$.

We further look into the performance of TOPAZ4 SIT in different sea areas as specified in Figure 1. There were 21 campaigns in the Beaufort Sea, 18 campaigns over the Central Arctic, 4 campaigns over the NOCAA, and 6 campaigns over the Chukchi Sea. Scatter plots in Figure 9 show that TOPAZ4 has the best fit in the Chukchi Sea. The minimum mean bias and the maximum mean CC are, as shown in Table $2,-0.07 \mathrm{~m}$ and 0.71 , respectively. These results agree somehow with that in Uotila and others (2019), who found smaller errors $(<0.25 \mathrm{~m})$ in TOPAZ4 in the Canada basin, the East Siberian Sea and some parts of the Chukchi Sea, even compared with the errors in other reanalysis products from 2000 to 2012 (see Fig. 5 in Uotila and others (2019)). The well-performed TOPAZ4 SIT during that period was also benefited from the assimilation of SIC. Consequently, it indicates that both the SIT assimilation and the internal thermodynamics of sea ice may play a part in the Chukchi Sea. For the thicker ice over the NOCAA, TOPAZ4 shows a bias of $-0.3 \mathrm{~m}$, indicating TOPAZ4 underestimates the SIT over the ridged ice area.

\subsubsection{Comparing with the IMB buoy SIT}

IMB buoys are designed to measure ice growth and ablation. As the equipment is attached to a piece of ice floe, the buoys mainly provide Lagrangian SIT information. Due to the different representations of SITs in TOPAZ4 and IMB buoy, we evaluate TOPAZ4 SIT by comparing the SIT evolution in TOPAZ4 and IMB (see section 3). The trajectory of each buoy is shown in Figure 10a and the performance of TOPAZ4 SIT is diagnosed against each buoy, as shown in Figure 10b. The mean normalized standard deviation is $1.45 \mathrm{~m}$ and the CRMSD is $0.48 \mathrm{~m}$. The mean CC between IMB and TOPAZ4 is 0.79 .

One representative buoy $(2013 \mathrm{~F})$ was chosen for a case study and its analysis is presented in Figure 11. Overall, TOPAZ4 is able to reproduce the SIT measured by buoy $2013 \mathrm{~F}$, with a correlation of 0.69 and a CRMSD of $0.21 \mathrm{~m}$. By analyzing this buoy data, we can gain an insight into the advantage and disadvantage of assimilating CS2SMOS SIT. When CS2SMOS SITs are close to IMB observations, so does the TOPAZ4 SIT (from January 2014 to May 2014). However, when large differences between the two exist, such as an abrupt decline in CS2SMOS 10 April 2015, assimilating the CS2SMOS SIT value can lead to a large thickness change in TOPAZ4 SIT and causes large misfit of TOPAZ4 SIT with IMB observational SIT. This deteriorates the performance of TOPAZ4 and induces large CRMSD. Even so, TOPAZ4 SIT grows back and it is very close to the IMB buoy observations by 25 June. What is more, a large difference between CS2SMOS and TOPAZ4 can be found from October 2014 to February 2015. This is because that we enlarged the observational error when assimilating CS2SMOS SIT and the SIT difference between CS2SMOS and TOPAZ4 could be reasonable if no more than 0.5 $\mathrm{m}$ (Xie and others, 2018). The large difference shown in Figure 11 may be related to the small ensemble spread.

TOPAZ4 reanalysis without SIT assimilation has performed better than that with SIT assimilation when compared to this IMB buoy $(2013 \mathrm{~F})$. This is due to assimilating the inaccurate CS2SMOS SIT 10 April 2015. However, this may be avoidable if the inaccurate CS2SMOS could be filtered out. This study helps identify some issues that existed in the current system. Overall, the impact of assimilating CS2SMOS SIT shows the promising effect when considering all IMB buoys' SIT, as a reduction of $8 \%$ in terms of CRMSD is observed.

\subsubsection{Comparing with SSO SIT}

The Sea State Campaign observes SIT in the Beaufort Sea and Chukchi Sea at a high frequency, which facilitates the performance evaluation for TOPAZ4 during the ice growth season in October 2015. Despite this campaign lasted only for about a month, the comparison with TOPAZ4 will consider the previous results when compared with ULS observation in October.

Figure 12 shows the comparison of SIT between TOPAZ4 and SSO along the trajectory of the SeaState Campaign. The descriptive statistics are also shown in Figure 12 for different regions. At $\sim 2$ November, the variation and the peak value are well simulated by TOPAZ4. However, TOPAZ4 generally fails to capture the peak and minimal thickness most of the time, for example, $\sim 21$ October. During this period, TOPAZ4 SIT has a good correlation with the observed SIT but underestimates SIT for $\sim 1 \mathrm{~m}$. The main reason for this big gap could be that the ship-observed ice does not represent the averaged SIT over a large area. Statistically, TOPAZ4 underestimates SIT by $\sim 0.03 \mathrm{~m}$ in the Chukchi Sea, but overestimates SIT by the same amount in the Beaufort Sea. Also, during the same period in ULS observations, the mean bias of TOPAZ4 SIT compared to the ULS observations is 0.21 $\mathrm{m}$. Therefore, we believe that TOPAZ4 reproduce thicker ice in the Beaufort Sea in October.

\section{Summary and discussions}

A 5-year TOPAZ4 SIT reanalysis product has been generated with the assimilation of SIC from OSISAF and SIT from CS2SMOS. In this study, TOPAZ4 SIT is evaluated with several reference datasets. Despite assimilating SIT reduced the SIT errors by $\sim 28 \%$ from 19 March 2014 to 31 March 2015 (Xie and others, 2018), quantified statistics remains to be made to figure out how TOPAZ4 perform based on more observations and over longer period.

Firstly, we compare TOPAZ4 SIT with CS2SMOS, CMST and PIOMAS. In March, TOPAZ4 simulates thinner ice compared with CS2SMOS, PIOMAS and CMST (Figs $3 \mathrm{a}-\mathrm{c}$ ), and thus 

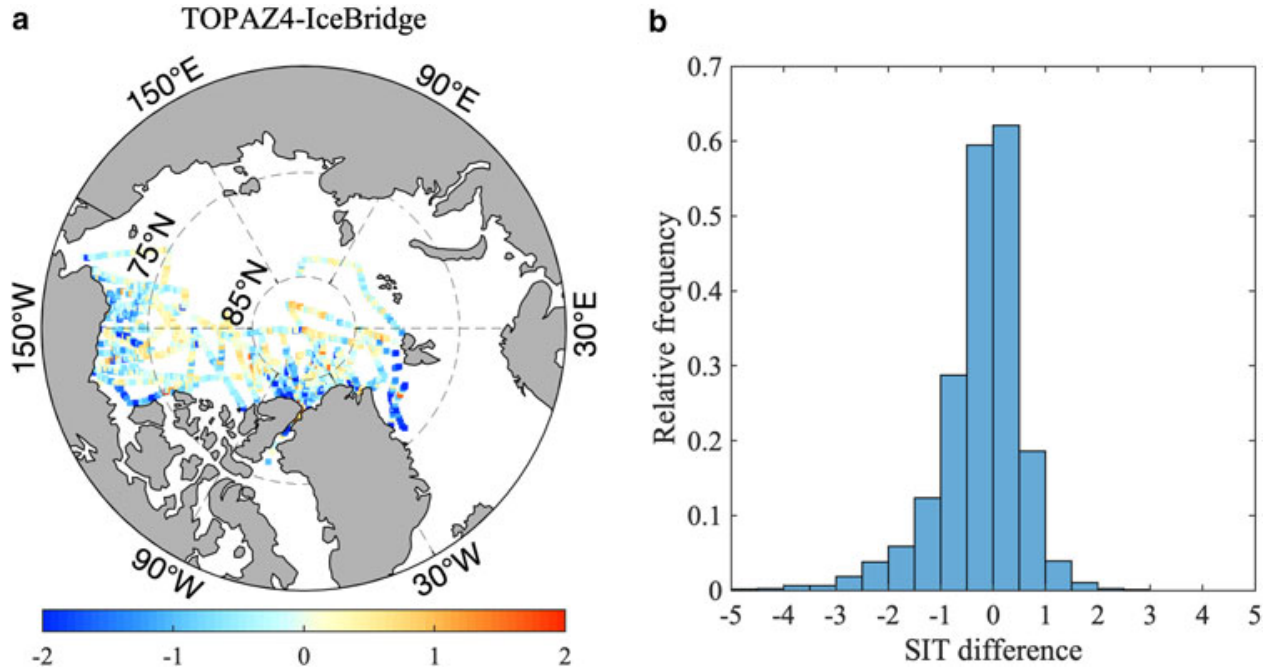

Fig. 7. Difference of SIT between TOPAZ4 and IceBridge Quicklook. (a) Spatial distribution and (b) probability distribution function of the SIT difference.
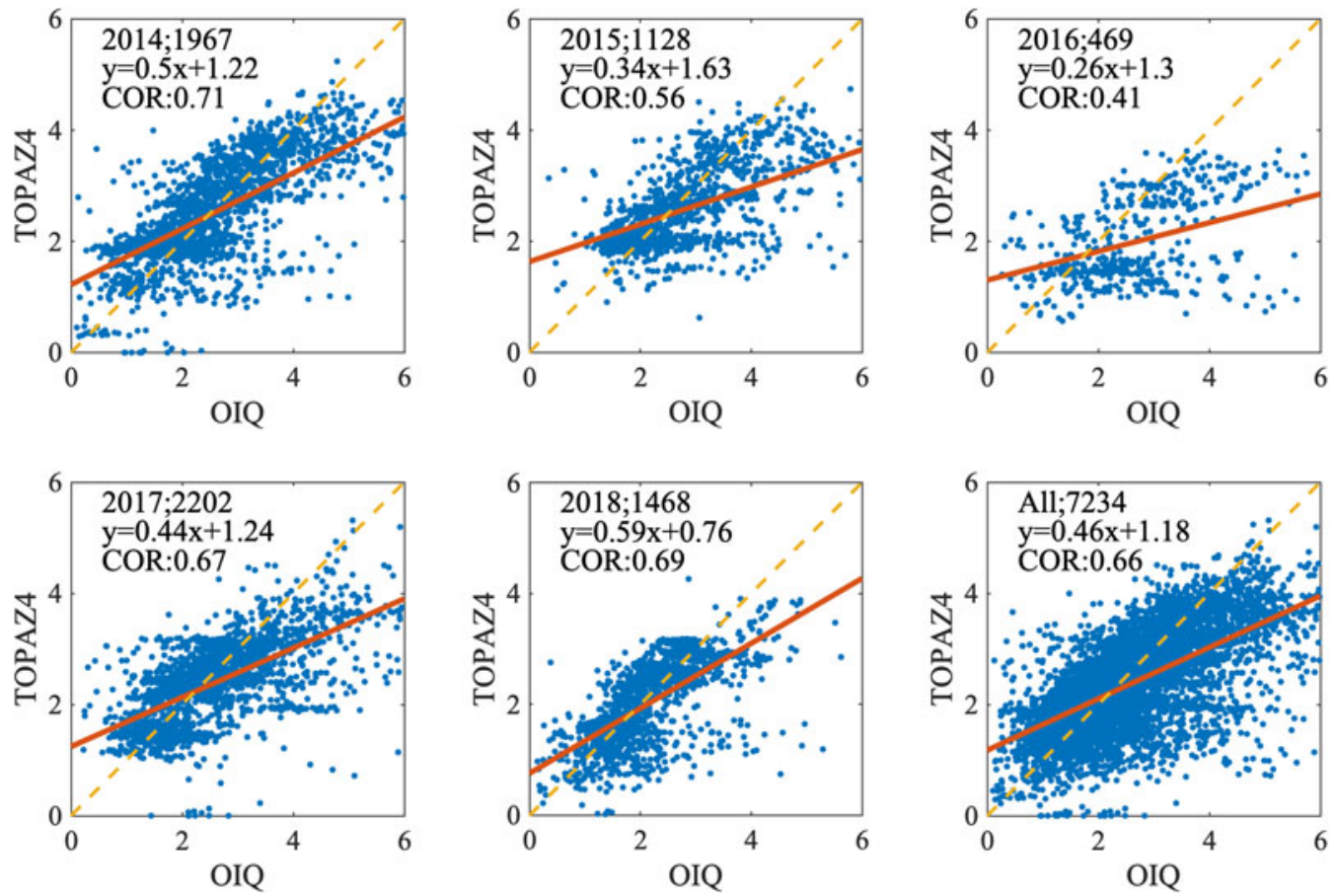

Fig. 8. SIT from TOPAZ4 ( $Y$-axis) and gridded averaged SIT from Operation IceBridge Quicklook ( $X$-axis). The years and the numbers of scatters are listed in the top left of each panel. 'All' represents all years from 2014 to 2018. Linear equations obtained from univariate linear fitting using SIT from IceBridge Quicklook and TOPAZ4 are given there. They are represented by tangerine lines in respective subplots. The correlations are given below the equations.

shows a smaller SIV in the Arctic Basin (Fig. 5). The RD mainly exists in the Atlantic Sector (Figs $4 \mathrm{a}-\mathrm{c}$ ). In September, the spatial SIT distribution between TOPAZ4 and other reference datasets shows few coincidences. TOPAZ4 SIT is much thicker than PIOMAS along the northern coast of CAA and the northwest of the Greenland, but it is close to CMST (Figs 3d, e). The larger $\mathrm{RD}$ mainly exists in the marginal ice area in September, different from that in March (Figs $4 \mathrm{~d}, \mathrm{e}$ ), and this difference may result from the different model dynamics.

Secondly, the performance of TOPAZ4 SIT is evaluated against most available in situ observations, including ULS, IceBridge, IMB and SSO. However, the evaluation has been hampered by the sparseness of the observational data. Among all the observations listed above, each observation has its own spatiotemporal coverage. For example, ULS provides SIT information year-round but is only limited to one specific location. On the contrary, IceBridge Quicklook measures SIT over the western Arctic with a long distance, but only for some days in the freezing season. The Sea State and the IMB buoy observations strike a balance between ULS and OIQ, as they provide us data with good spatial coverage (compared with ULS) for a relatively longer period (compared with IceBridge). To make the best use of these in situ observations, we focus on the same period and the same sea area that in situ observations and TOPAZ4 overlap. We evaluate the TOPAZ4 SIT in March-April based on ULS and IceBridge observations, and in October based on SSO and ULS observations. We also assess TOPAZ4 SIT in the Beaufort Sea with data from ULS, OIQ and SSO.

We noticed the consistent variability but different values of bias in TOPAZ4 SIT when comparing to different observational 
Fig. 9. SIT from TOPAZ4 ( $Y$-axis) and gridded averaged SIT from Operation IceBridge Quicklook ( $X$-axis) in the Beaufort Sea (a), the Central Arctic (b), the Chukchi Sea (c) and north of the Canadian Arctic Archipelago (NOCAA), (d). The sea areas and the numbers of scatters are listed in the top left of each panel. The linear equations obtained from univariate linear fitting using SIT from IceBridge Quicklook and TOPAZ4 are also given there, which are represented by tangerine lines in respective subplots. The correlations are given below the equations.
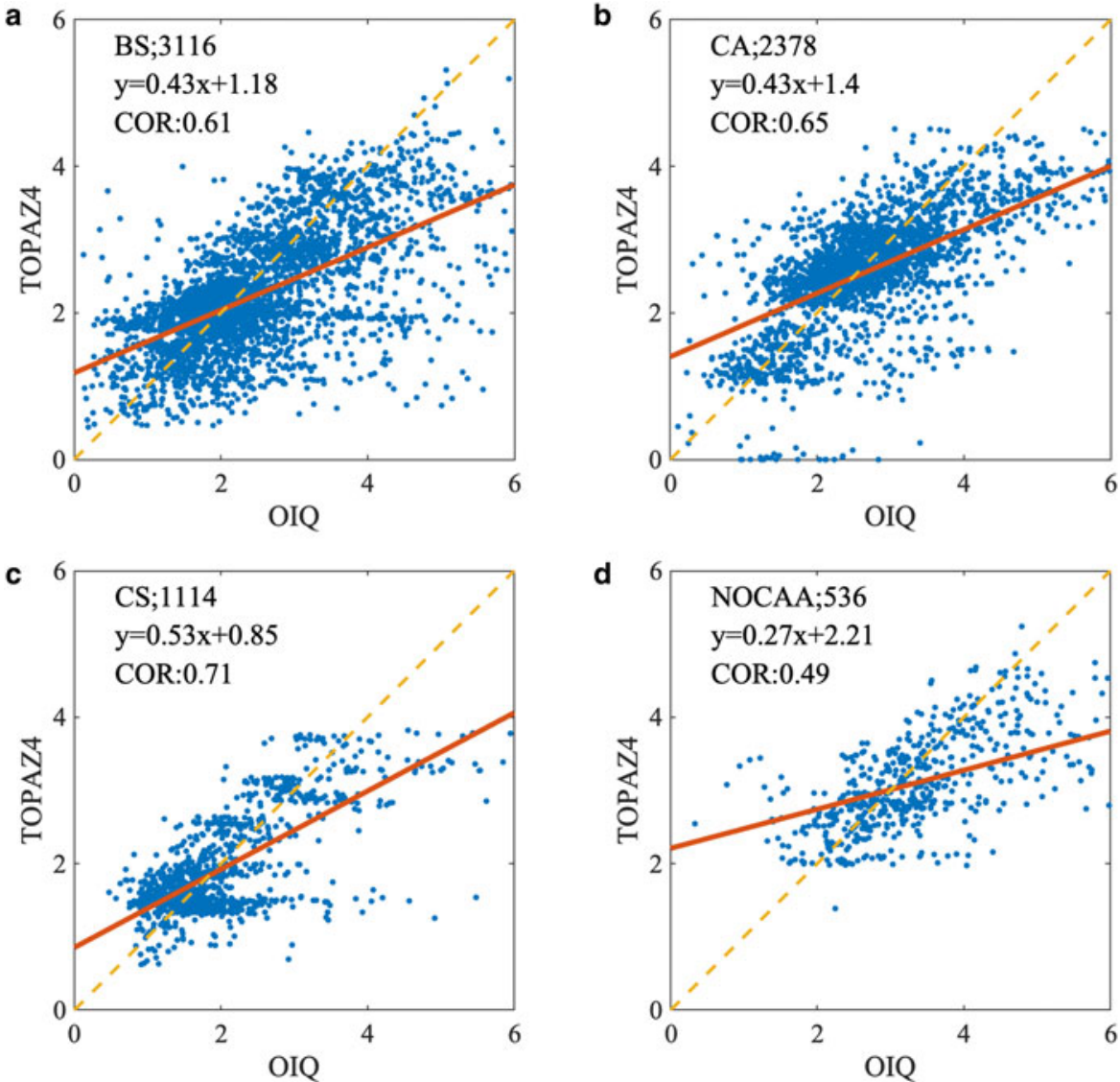

Table 2. The CC (correlation coefficient), bias (in $\mathrm{m}$ ) and RMSD (in $\mathrm{m}$ ) for the TOPAZ4 SIT with respect to IceBridge Quicklook in different years

\begin{tabular}{|c|c|c|c|c|c|c|c|}
\hline Year & & 2014 & 2015 & 2016 & 2017 & 2018 & All time \\
\hline \multirow[t]{5}{*}{$\mathrm{CC}$} & BS & 0.74 & 0.55 & 0.19 & 0.57 & 0.70 & 0.61 \\
\hline & CA & 0.65 & 0.52 & 0.37 & 0.68 & 0.55 & 0.65 \\
\hline & $\mathrm{CS}$ & - & 0.64 & - & -0.18 & 0.74 & 0.71 \\
\hline & NOCAA & 0.58 & 0.40 & - & - & - & 0.49 \\
\hline & All regions & 0.71 & 0.56 & 0.41 & 0.67 & 0.69 & 0.66 \\
\hline \multirow[t]{5}{*}{ bias } & BS & 0.06 & -0.27 & -0.76 & -0.60 & -0.24 & -0.25 \\
\hline & CA & -0.50 & -0.31 & -0.63 & -0.06 & 0.02 & -0.17 \\
\hline & $\mathrm{CS}$ & - & -0.10 & - & -0.06 & -0.07 & -0.07 \\
\hline & NOCAA & -0.19 & -0.60 & - & - & - & -0.3 \\
\hline & All regions & -0.13 & -0.27 & -0.73 & -0.20 & 0.12 & -0.21 \\
\hline \multirow[t]{5}{*}{ RMSD } & $\mathrm{BS}$ & 0.70 & 1.06 & 1.40 & 1.18 & 0.76 & 0.95 \\
\hline & CA & 1.33 & 0.86 & 1.21 & 0.75 & 0.62 & 0.90 \\
\hline & $\mathrm{CS}$ & - & 0.81 & - & 0.50 & 0.60 & 0.64 \\
\hline & NOCAA & 0.95 & 1.53 & - & - & - & 1.14 \\
\hline & All regions & 0.93 & 1.04 & 1.36 & 0.87 & 0.66 & 0.92 \\
\hline
\end{tabular}

BS=Beaufort Sea; $C A=$ Central Arctic; $C S=C h u k c h i$ Sea; NOCAA=north of the Canadian Arctic Archipelago. Note that the bias represents TOPAZ4 minus IceBridge Quicklook.

All time means the time coverage of IceBridge Quicklook flight campaigns during the freezing season.

SITs. Comparing with ULS, TOPAZ4 overestimates the mean SIT in the Beaufort Sea by $\sim 0.11 \mathrm{~m}$ averaged from 2014 to 2018 (Fig. 6), with the maximum overestimation in summer (Table 1). In October, the overestimation of SIT in the Beaufort Sea is only $0.03 \mathrm{~m}$ against SSO (Fig. 12) but $0.21 \mathrm{~m}$ against ULS (Fig. 6). Nonetheless, in March and April, TOPAZ4 underestimates SIT in the Beaufort Sea with a bias of $-0.25 \mathrm{~m}$ comparing with IceBridge Quicklook (Fig. 9a and Table 2) and $-0.06 \mathrm{~m}$ against ULS (Fig. 6). Actually, TOPAZ4 seems to underestimate SIT in most regions from March to April. The maximum underestimation occurs along the northern coast of CAA based on IceBridge Quicklook, with a bias of $-0.3 \mathrm{~m}$ and a RMSD of
$1.14 \mathrm{~m}$, the bias is relatively smaller over thin ice areas, such as in the Chukchi Sea $(-0.07 \mathrm{~m})$. Using the buoy data for evaluation, TOPAZ4 has a good correlation with the IMB SIT, with a mean CC of 0.79. Compared to TOPAZ4 reanalysis without SIT assimilation, the benefit from assimilating CS2SMOS SIT shows an improvement of $\sim 8 \%$ in terms of CRMSD.

As shown in Figures 34 , the differences between different products have potentially large values in some particular regions, including the Fram Strait, the NOCAA and the north of Greenland Island. This implies that a sophisticated sea ice-ocean model, data assimilation scheme and more in situ observations are urgently needed. For example, to improve the simulation 
a

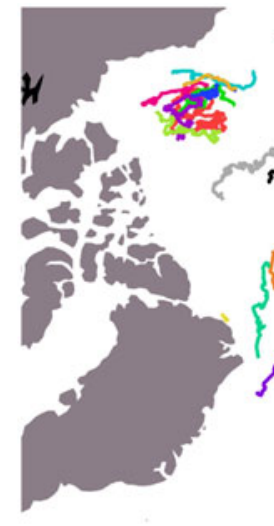

2015B

2014D

2013F

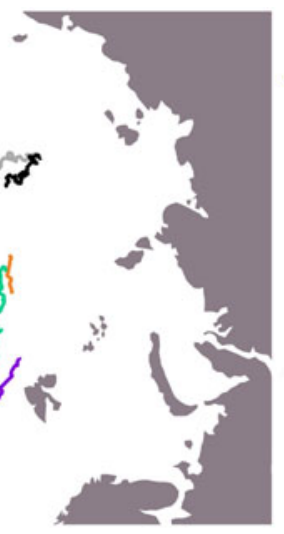

b

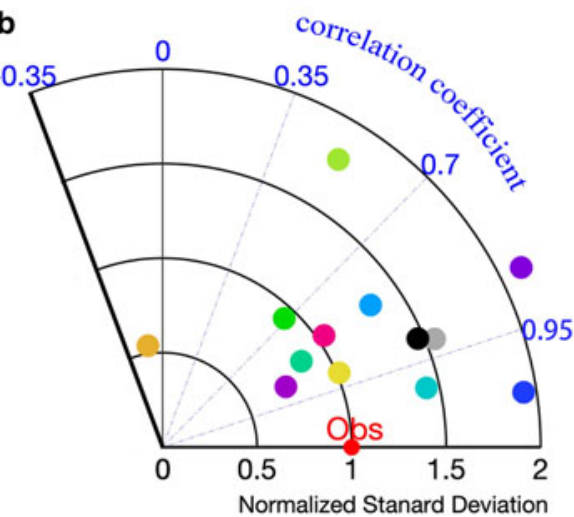

$2015 \mathrm{~F}$

20141

2014B
2015G

2015A

$2014 C$

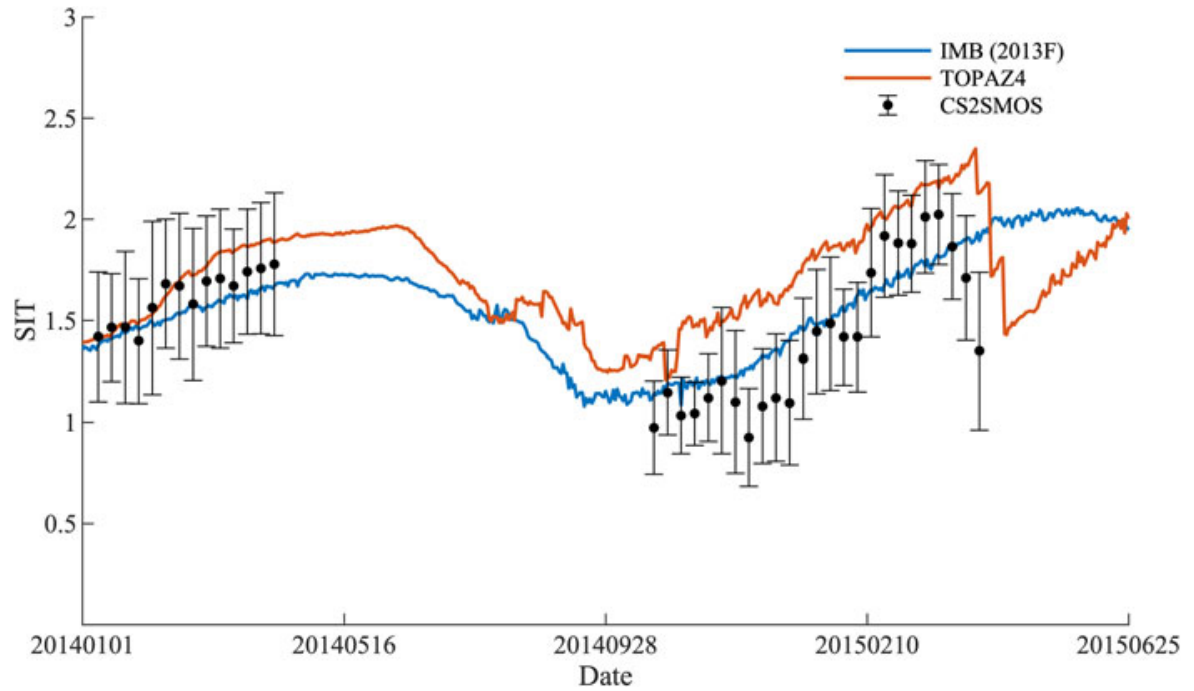

Fig. 10. (a) The trajectories of all available IMB buoys and (b) Taylor diagram for TOPAZ4 SITs with respect to all available IMB buoys data. The radial axis is the Normalized Standard Deviation and the angular axis represents the correlation coefficient. Each circle represents the performance of TOPAZ4 based on one single IMB.

Fig. 11. Time series of SIT for IMB buoy (2013F, blue line), TOPAZ4 (tangerine line) and CS2SMOS (black dot). The error bar represents the corresponding uncertainty of CS2SMOS SIT. Date format is YYYYMMDD.

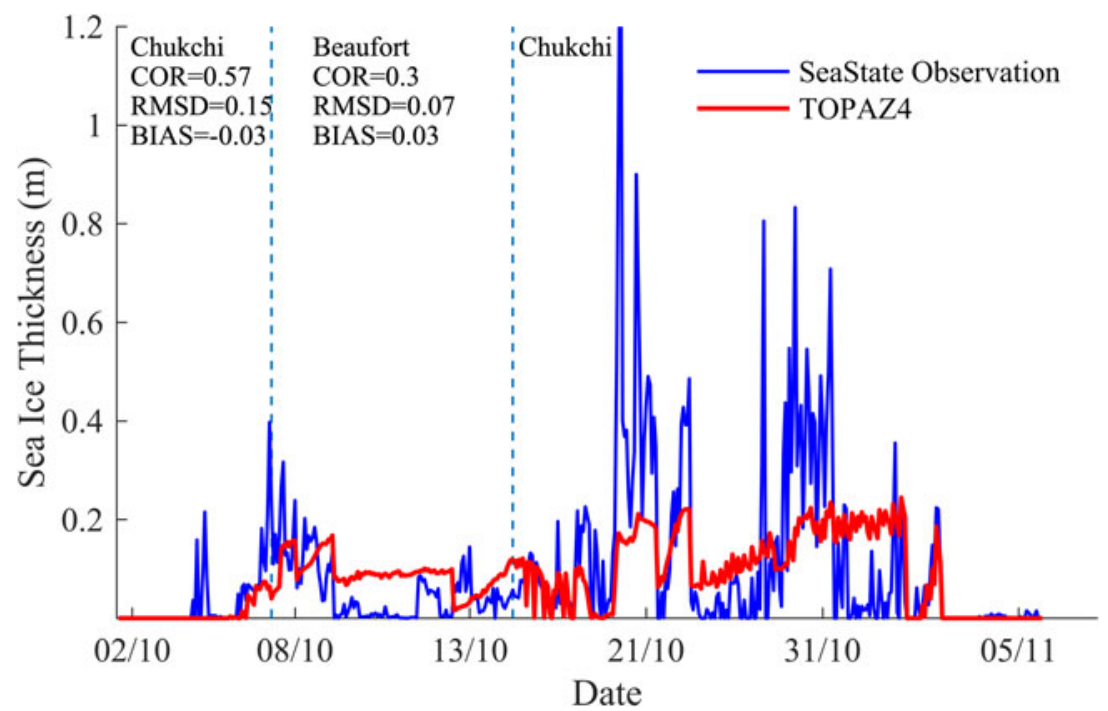

Fig. 12. Time series of SIT along the trajectory of the Sea State Campaign (blue line) and TOPAZ4 SIT (red line) during October 2015 . along the northern coast of CAA, it is crucial to understand the mechanism of the formation, maintenance and decay of coastal landfast ice (Lemieux and others, 2015). In order to further reduce the shortcoming of SIT simulation, more realistic physical processes (such as melt pond in summer) in the sea-ice model (Holland and others, 2012) and a more accurate atmospheric forcing are both expected to be developed further. Arctic-wide observational SIT is also needed for assimilation and corroboration, 
especially during the summer when satellite-derived SIT is not available. In addition, the differences of SIT between TOPAZ4 and CMST/PIOMAS in September are significantly larger than that in March and there are more complicated dynamic conditions (e.g. melting and freezing are purely local, but sea-ice deformations, opening and ridging are far-reaching processes; Rampal and others, 2008) in the central Arctic. There is still a long way to reconstruct a consistent time series of Arctic SIT and SIV especially during the melting season.

During the process of generating a reanalysis product, TOPAZ4 assimilates CS2SMOS, which is a merged product from SMOS and CryoSat-2 using an optimal interpolation scheme. Assimilating the merged CS2SMOS is straightforward and easy to implement for operational forecast system, but the uncertainty of the merged product is difficult to quantify. In fact, one can improve the assimilation strategy by assimilating different SIT products. For example, Mu and others (2018b) jointly assimilates SIT and their respective uncertainties from SMOS and CryoSat-2 individually into CMST, and the results presented a better performance of SIT than assimilating CS2SMOS directly. This can be explained by that uncertainties in SMOS and CryoSat-2 SIT are quantified more explicitly than those in CS2SMOS, which has a positive effect of the assimilation performance ( $\mathrm{Mu}$ and others, 2018b). Recently, using a stochastic ensemble Kalman filter semiqualitative (EnKF-SQ) method, Shah and others (2019) showed the advantages of assimilating range-limited thin ice thickness measurement, compared with the results from neglecting the out-of-range value in EnKF. Furthermore, Sallila and others (2019) showed the CryoSat-2 SIT are reliable between 0.5 and $4 \mathrm{~m}$, so the EnKF-SQ will be promising to seamlessly assimilate these two range-limited SIT observations from CryoSat- 2 and SMOS (SIT $<0.5 \mathrm{~m}$ ). It is expected that more precise definitions of the observation errors of satellite-derived SIT are promising to further improve the assimilation performance.

Data availability. The observations used for evaluation, including ULS, IMB, OIQ and SSO, are available from the sources mentioned in the text. The PIOMAS product can be download as mentioned in the corresponding chapter. The CMST SIT products are available at https://doi.org/10.1594/ PANGAE A.891475 (Mu and others, 2018c). The CS2SMOS SIT product can be downloaded from https://data.seaiceportal.de/data/cs2smos_awi/n/ (Ricker and others, 2017). The TOPAZ4 reanalysis data are available at http://marine.copernicus.eu (Xie and others, 2018).

Acknowledgements. This study is supported by the National Key R\&D Program of China (Grant No. 2019YFA0607004), the National Natural Science Foundation of China (No. 41922044, 41941009, 41676185), the Guangdong Basic and Applied Basic Research Foundation (No. 2020B1515020025), and the Fundamental Research Funds for the Central Universities (No. 19lgzd07). This is a contribution to the Year of Polar Prediction (YOPP), a flagship activity of the Polar Prediction Project (PPP), initiated by the World Weather Research Programme (WWRP) of the World Meteorological Organisation (WMO). We acknowledge the WMO WWRP for its role in coordinating this international research activity. We thank two anonymous reviewers and the scientific editor Stephen Jones for their valuable comments to help improve our manuscript.

Author contributions. QY and JX developed the concept of the paper. YX performed the data analysis and interpretation of the results. All co-authors assisted during the writing process and critically discussed the contents.

Conflict of interests. The authors declare that they have no conflict of interest.

\section{References}

Bouillon S, Fichefet T, Legat V and Madec G (2013) The elastic-viscousplastic method revisited. Ocean Modelling 71, 2-12. doi: 10.1016/j.ocemod.2013.05.013.
Cavalieri DJ and Parkinson CL (2012) Arctic Sea ice variability and trends, 1979-2010. The Cryosphere 6(4), 881-889. doi: 10.5194/tc-6-881-2012.

Chassignet EP and 6 others (2006) Ocean prediction with the hybrid coordinate ocean model (HYCOM). In Chassignet EP and Verron J eds. Ocean Weather Forecasting, Springer, Dordrecht, pp. 413-426. doi: 10.21236/ada482374.

Comiso JC and Hall DK (2014) Climate trends in the Arctic as observed from space. Wiley Interdisciplinary Reviews: Climate Change 5(3), 389-409. doi: 10.1002/wcc.277.

Connor LN, Laxon SW, Ridout AL, Krabill WB and McAdoo DC (2009) Comparison of Envisat radar and airborne laser altimeter measurements over Arctic sea ice. Remote Sensing of Environment 113(3), 563-570. doi: 10.1016/j.rse.2008.10.015.

Hendricks S, Paul S and Rinne E (2018) ESA Sea Ice Climate Change Initiative (Sea_Ice_cci): Northern hemisphere sea ice thickness from the Envisat satellite on a monthly grid (L3C), v2.0. Centre for Environmental Data Analysis, date of citation. doi: 10.5285/f4c34f4fofld4d0da06d771f6972f180.

Hibler III WD (1979) A dynamic thermodynamic sea ice model. Journal of Physical Oceanography 9(4), 815-846. doi: 10.1007/978-3-642-85016-5_37.

Holland MM, Bailey DA, Briegleb BP, Light B and Hunke E (2012) Improved sea ice shortwave radiation physics in CCSM4: the impact of melt ponds and aerosols on Arctic sea ice. Journal of Climate 25(5), 1413-1430, doi: 10.1175/JCLI-D-11-00078.1.

Hunke EC and Dukowicz JK (1997) An elastic-viscous-plastic model for sea ice dynamics. Journal of Physical Oceanography 27(9), 1849-1867. doi: 10. 1175/1520-0485(1997)027<1849:aevpmf>2.0.co;2.

Kaleschke L and 5 others (2010) A sea-ice thickness retrieval model for 1.4 $\mathrm{GHz}$ radiometry and application to airborne measurements over low salinity sea-ice. The Cryosphere 4(4), 583-592. doi: 10.5194/tc-4-583-2010.

King J and 8 others (2015) Evaluation of operation IceBridge quick-look snow depth estimates on sea ice. Geophysical Research Letters 42(21), 9302-9310. doi: $10.1002 / 2015$ gl066389.

Krishfield R and Proshutinsky A (2006) BGOS ULS Data Processing Procedure, Woods Hole Oceanographic Institution, March 2006, 14 pp.

Kurtz NT and 8 others (2013) Sea ice thickness, freeboard, and snow depth products from Operation IceBridge airborne data. The Cryosphere 7(4), 1035-1056. doi: 10.5194/tc-7-1035-2013.

Kurtz NT, Markus T, Farrell SL, Worthen DL and Boisvert LN (2011) Observations of recent Arctic sea ice volume loss and its impact on ocean-atmosphere energy exchange and ice production. Journal of Geophysical Research: Oceans 116(C4), C04015. doi: 10.1029/2010JC006235.

Kwok R and 5 others (2009) Thinning and volume loss of the Arctic Ocean sea ice cover. Journal of Geophysical Research: Oceans 114(C7), C07005. doi: 10.1029/2009JC005312.

Kwok R and Cunningham GF (2015) Variability of Arctic sea ice thickness and volume from CryoSat-2. Philosophical Transactions of The Royal Society A 373(2045), 20140157. doi: 10.1098/rsta.2014.0157.

Laxon S, Peacock N and Smith D (2003) High interannual variability of sea ice thickness in the Arctic region. Nature 425(6961), 947-950. doi: 10.1038/ nature 02050 .

Lemieux and 5 others (2015) A basal stress parameterization for modeling landfast ice. Journal of Geophysical Research: Oceans 120(4), 3157-3173. doi: 10.1002/2014JC010678.

Lindsay R and Schweiger A (2015) Arctic Sea ice thickness loss determined using subsurface, aircraft, and satellite observations. The Cryosphere 9(1), 269-283. doi: 10.5194/tc-9-269-2015.

Lindsay $\mathbf{R}$ and Zhang $\mathbf{J}$ (2006) Assimilation of ice concentration in an iceocean model. Journal of Atmospheric and Oceanic Technology 23(5), 742749. doi: $10.1175 /$ jtech1871.1.

Losch M, Menemenlis D, Campin JM, Heimbach P and Hill C (2010) On the formulation of sea-ice models. Part 1: effects of different solver implementations and parameterizations. Ocean Modelling 33(1-2), 129-144. doi: j.ocemod.2009.12.008

Marshall J, Adcroft A, Hill C, Perelman L and Heisey C (1997) A finitevolume, incompressible Navier Stokes model for studies of the ocean on parallel computers. Journal of Geophysical Research: Oceans 102(C3), 5753-5766. doi: 10.1016/j.compfluid.2020.104434.

Meier WN and 11 others (2014) Arctic sea ice in transformation: a review of recent observed changes and impacts on biology and human activity. Reviews of Geophysics 52(3), 185-217. doi: 10.1002/2013rg000431.

Melia N, Haines K, Hawkins E and Day JJ (2017) Towards seasonal Arctic shipping route predictions. Environmental Research Letters 12(8): 084005. doi: $10.1088 / 1748-9326 / \mathrm{aa} 7 \mathrm{a} 60$. 
Melling H, Johnston PH and Riedel DA (1995) Measurements of the underside topography of sea ice by moored subsea sonar. Journal of Atmospheric and Oceanic Technology 12(3), 589-602. doi: 10.1175/1520-0426(1995) 012<0589:motuto $>2.0$. co;2.

Min C and 7 others (2019) Sea ice export through the Fram Strait derived from a combined model and satellite data set. The Cryosphere 13(12) 3209-3224. doi: 10.5194/tc-13-3209-2019.

Mu L and 5 others (2018a) Arctic-Wide Sea Ice thickness estimates from combining satellite remote sensing data and a dynamic Ice-ocean model with data assimilation during the CryoSat-2 period. Journal of Geophysical Research: Oceans 123(11), 7763-7780. doi: 10.1029/2018jc014316.

Mu L and 7 others (2018b) Improving sea ice thickness estimates by assimilating CryoSat-2 and SMOS sea ice thickness data simultaneously. Quarterly Journal of the Royal Meteorological Society 144(711), 529-538. doi: 10.1002/ qj.3225.

Mu L and 5 others (2018c) The Arctic combined model and satellite sea ice thickness (CMST) dataset PANGAEA. doi: 10.1594/PANGAEA.891475.

Nerger L and Hiller W (2013) Software for ensemble-based data assimilation systems-implementation strategies and scalability. Computers \& Geosciences 55, 110-118. doi: 10.1016/j.cageo.2012.03.026.

Nguyen AT, Menemenlis D and Kwok R (2011) Arctic Ice-ocean simulation with optimized model parameters: approach and assessment. Journal of Geophysical Research: Oceans 116(C4), C04025. doi: 10.1029/2010jc006573.

Perovich D and 5 others (2009) Observing and understanding climate change: monitoring the mass balance, motion, and thickness of Arctic sea ice. Available at http://imb. crrel. usace. army. mil.

Persson POG and 8 others (2018) Shipboard observations of the meteorology and near-surface environment during autumn freezeup in the Beaufort/ Chukchi seas. Journal of Geophysical Research: Oceans 123(7), 4930-4969. doi: $10.1029 / 2018 \mathrm{jc} 013786$.

Posey PG and 9 others (2015) Improving Arctic sea ice edge forecasts by assimilating high horizontal resolution sea ice concentration data into the US Navy's ice forecast systems. The Cryosphere 9(4), 1735-1745. doi: 10. 5194/tc-9-1735-2015.

Rampal P, Weiss J, Marsan D, Lindsay R and Stern H (2008) Scaling properties of sea ice deformation from buoy dispersion analysis. Journal of Geophysical Research: Oceans 113(C3), C03002. doi: 10.1029/2007JC004143.

Richter-Menge JA and 5 others (2006) Ice mass-balance buoys: a tool for measuring and attributing changes in the thickness of the Arctic sea-ice cover. Annals of Glaciology 44, 205-210. doi: 10.3189/172756406781811727.

Ricker R and 5 others (2017) A weekly Arctic sea-ice thickness data record from merged CryoSat-2 and SMOS satellite data. The Cryosphere 11(4), 1607-1623. doi: 10.5194/tc-11-1607-2017.

Ricker R, Hendricks S, Helm V, Skourup H and Davidson M (2014) Sensitivity of CryoSat-2 Arctic sea-ice freeboard and thickness on radarwaveform interpretation. The Cryosphere 8(4), 1607-1622. doi: 10.5194/ tc-8-1607-2014.

Rothrock DA, Yu Y and Maykut GA (1999) Thinning of the Arctic sea-ice cover. Geophysical Research Letters 26(23), 3469-3472. doi: 10.1029/ 1999GL010863.

Sakov P and 5 others (2012) TOPAZ4: an ocean-sea ice data assimilation system for the North Atlantic and Arctic. Ocean Science 8(4), 633-656, doi: 10. 5194/os-8-633-2012.

Sallila H, Farrell SL, McCurry J and Rinne E (2019) Assessment of contemporary satellite sea ice thickness products for Arctic sea ice. The Cryosphere 13(4), 1187-1213. doi: 10.5194/tc-13-1187-2019.

Schweiger A and 5 others (2011) Uncertainty in modeled Arctic sea ice volume. Journal of Geophysical Research: Oceans 116(C8), C00D06. doi: 10. 1029/2011jc007084.
Semtner J and Albert J (1976) A model for the thermodynamic growth of sea ice in numerical investigations of climate. Journal of Physical Oceanography 6(3): 379-389. doi: 10.1175/1520-0485(1976)006<0379:amfttg>2.0.co;2.

Serreze MC and Meier WN (2019) The Arctic's sea ice cover: trends, variability, predictability, and comparisons to the Antarctic. Annals of The New York Academy of Sciences 1436(1), 36-53. doi: 10.1111/nyas.13856.

Sévellec F, Fedorov AV and Liu W (2017) Arctic sea-ice decline weakens the Atlantic Meridional overturning circulation. Nature Climate Change 7(8), 604-610. doi: 10.1038/nclimate3353.

Shah A, Bertino L, Counillon F, El Gharamti M and Xie J (2019), Assimilation of semi-qualitative sea ice thickness data with the EnKF-SQ: a twin experiment, Tellus A: Dynamic Meteorology and Oceanography $\mathbf{7 2}$ (1), 1-15. doi: 10.1080/16000870.2019.1697166.

Stroeve J and Notz D (2015) Insights on past and future sea-ice evolution from combining observations and models. Global and Planetary Change 135, 119-132, doi: 10.1016/j.gloplacha.2015.10.011.

Taylor KE (2001) Summarizing multiple aspects of model performance in a single diagram. Journal of Geophysical Research: Atmospheres 106(D7), 7183-7192. doi: 10.1029/2000jd900719.

Tian-Kunze X and 6 others (2014) SMOS-derived thin sea ice thickness: algorithm baseline, product specifications and initial verification. The Cryosphere 8(3), 997-1018. doi: 10.5194/tc-8-997-2014.

Tilling RL, Ridout A and Shepherd A (2016) Near-real-time Arctic sea ice thickness and volume from CryoSat-2. The Cryosphere 10(5), 2003-2012. doi: 10.5194/tc-2016-21-rc1.

Uotila P and 9 others (2019) An assessment of ten ocean reanalyses in the polar regions. Climate Dynamics 52(3-4), 1613-1650. doi: 10.1029/2006jd007859.

Wang X, Key J, Kowk R and Zhang J (2016) Comparison of arctic sea ice thickness from Satellites, Aircraft, and PIOMAS data. Remote Sensing $\mathbf{8}$ (9), 713. doi: 10.3390/rs8090713.

Warren SG and 6 others (1999) Snow depth on Arctic sea ice. Journal of Climate 12(6), 1814-1829. doi: 10.1175/1520-0442(1999)012<1814: SDOASI $>2.0 . \mathrm{CO} ; 2$.

Xie J, Bertino L, Counillon F, Lisæter KA and Sakov P (2017) Quality assessment of the TOPAZ4 reanalysis in the Arctic over the period 1991-2013. Ocean Science 13(1), 123-144. doi: 10.5194/os-13-123-2017.

Xie J, Counillon F and Bertino L (2018) Impact of assimilating a merged sea-ice thickness from CryoSat-2 and SMOS in the Arctic reanalysis. The Cryosphere 12(11), 3671-3691. doi: 10.5194/tc-12-3671-2018.

Xie J, Counillon F, Bertino L, Tian-Kunze X and Kaleschke L (2016) Benefits of assimilating thin sea ice thickness from SMOS into the topaz system. Cryosphere 10(6), 2745. doi: 10.5194/tc-10-2745-2016.

Yang $\mathbf{Q}$ and 7 others (2014) Assimilating SMOS sea ice thickness into a coupled ice-ocean model using a local SEIK filter. Journal of Geophysical Research: Oceans 119(10), 6680-6692. doi: 10.1002/2014JC009963.

Yang Q, Losch M, Losa SN, Jung T and Nerger L (2016) Taking into account atmospheric uncertainty improves sequential assimilation of SMOSs sea ice thickness data in an ice-ocean model. Journal of Atmospheric and Oceanic Technology 33(3), 397-407. doi: 10.1175/ JTECH-D-15-0176.1.

Zhang J and Hibler III WD (1997) On an efficient numerical method for modeling sea ice dynamics. Journal of Geophysical Research: Oceans 102 (C4), 8691-8702. doi: 10.1029/96jc03744.

Zhang Y, Hu H and Dai L (2020) Real-time assessment and prediction on maritime risk state on the Arctic route. Maritime Policy \& Management 47(3). doi: doi: 10.1080/03088839.2019.1693064.

Zhang J and Rothrock DA (2003) Modeling global sea ice with a thickness and enthalpy distribution model in generalized curvilinear coordinates. Monthly Weather Review 131(5), 845-861, doi: 10.1175/1520-0493(2003) $131<0845$ :Mgsiwa>2.0.Co;2. 